\title{
An Observer-Based Robust Load Frequency Control
}

\author{
Dr R.K. Mehta ${ }^{1}$, Mr. Rittu Angu ${ }^{2}$ \\ ${ }^{1}$ Associate Prof. Elect. Engg. Dept., NERIST (Deemed University) Nirjuli Itanagar, India. \\ ${ }^{2}$ Scholar, Elect. Engg. Dept., NERIST (Deemed University) Nirjuli Itanagar, India.
}

\begin{abstract}
A full-order observer-based state feedback linear controller design approach for a single area load frequency problem is presented. The load frequency control model incorporates integral control for improved command tracking response and disturbance rejection. A full state feedback is implemented through full-order state observer design. State feedback with integral controllers design is carried out through a pole-placement technique using symmetrical root locus method. Parametric model uncertainty has been considered and stability robustness study has been carried out assigning a bound on the deviations in parameters of single area load frequency model. The proposed design methodology achieves performance satisfying the specified stability margins. The methodology provides a control over peak values of the frequency and control signal deviations which may be utilized to meet hardware constraints. A numerical example illustrates the effectiveness of the developed methodology.
\end{abstract}

Keywords: Load frequency control, Control area, Integral control, Full order state observer, Augmented system, MATLAB simulation.

$\begin{array}{lll}\text { Notations } & \mathrm{r}_{0}, \mathrm{r}_{1}, \mathrm{r}_{2} & \text { roots of characteristic equation of observer } \\ \mathrm{r} & \text { reference signal or set-point } \\ \lambda_{0}, \lambda_{1}, \lambda_{2} & \text { roots of characteristic equation of plant } \\ \rho & \text { system weighting penalty from SRL equation } \\ \rho_{\mathrm{i}} & \text { weighting penalty assigned to system due to integrator } \\ \mathrm{u} & \text { control force/signal/input } \\ \mathrm{T}_{\mathrm{s}} & \text { settling time, } \mathrm{s} \\ \mathrm{T}_{\mathrm{H}} & \text { hydraulic time constant, } \mathrm{s} \\ \mathrm{T}_{\mathrm{T}} & \text { turbine time constant, } \mathrm{s} \\ \mathrm{T}_{\mathrm{p}} & \text { generator/power system time constant, } \mathrm{s} \\ \mathrm{K}_{\mathrm{p}} & \text { proportional gain of generator/power system, puHz/Mw } \\ \mathrm{R} & \text { proportional speed regulation controller gain, puHz/Mw } \\ \hat{x} & \text { estimated state variables } \\ \mathrm{K}_{\mathrm{i}} & \text { integral gain } \\ \mathrm{K}\left(\mathrm{k}_{1}, \mathrm{k}_{2}, \mathrm{k}_{3}\right) & \text { feedback gains } \\ \mathrm{e} & \text { error signal } \\ \mathrm{w} & \text { Disturbance } \\ \mathrm{s} & \text { Laplace variable }\end{array}$

\section{Introduction}

Fortunately and unfortunately, our system load demand $\mathrm{P}_{\mathrm{D}}$ and $\mathrm{Q}_{\mathrm{D}}$ are never steady [10]. They keep on changing all the time throughout the day, month or year and the change is also random with time. Steam input to the steam-turbine and water input the hydro-generator must therefore be continuously regulated to match the active power demand, failing which the frequency (machine speed) will vary. Since the maximum allowable permissible frequency in India is $\pm 2.5 \%$, so a constant match is going on between them to keep track of each 
other to maintain constant frequency operation of the system which is $50 \mathrm{H}_{\mathrm{Z}}$. Also the excitation of generators must also be continuously regulated to match $\mathrm{Q}_{\mathrm{D}}$ with reactive generation, otherwise voltages at various system buses may go beyond the prescribed limits.

It is well known that three-phase alternating current $(\mathrm{AC})$ is generally used to transport the electricity. Thus, during the transportation, both the active power balance and the reactive power balance must be maintained between generating and utilizing the $\mathrm{AC}$ power. When either of the two balances is broken and reset at a new level, the equilibrium points will float [5]. A good quality of the electric power system requires both the frequency and voltage to remain at standard values during operation.

However, the users of the electric power change the loads randomly and momentarily. Thus, a control system is essential to cancel the effects of the random load changes and to keep the frequency and voltage at the standard values. Although the active power and reactive power have combined effects on the frequency and voltage, the control problem of the frequency and voltage can be decoupled into two independent problems. One is about the active power and frequency control while the other is about the reactive power and voltage control. The active power and frequency control is referred to as load frequency control (LFC) [8]. The latter is known as automatic voltage regulator (AVR) [1]. The two control loops does not interfere with each other due to the fact that relationship between them in very weak. That is, the time constant between them is entirely different, former is a faster control and the latter is a slower one [10].

The present work attempts to utilize full state feedback for single area load frequency controller design. The control objective is to develop a procedure for designing state feedback and integral controllers for a given plant conditions, the specifications set as:

(i) No deviation in frequency in steady-state for a step change in load demand.

(ii) Critical gain and phase margins must be greater or equal to the specified GM and PM.

It is assumed that the load frequency model parameters (i.e. $R, T_{H}, T_{T}, T_{p}$ and $K_{p}$ ) are given, output ( $f$ ) is available for feedback. State feedback has potential to improve the performance of the load frequency by judicious choice of closed-loop pole locations. A full state observer has been constructed to meet the performance requirements and iterative design steps are required to ensure satisfactory operation. The LFC model incorporates integral control for improved command tracking and to enhance disturbance rejection capability for the proposed control scheme. Moreover, a realistic LFC system having uncertain variations in parameters from their nominal values will be characterized by deviations in the nominal values of LFC parameters $\left(T_{H}, T_{T}, T_{p}, H, D\right)$. In this paper, the parametric model uncertainty has been considered, which represents imprecision of the parameters within the model. The observer-based closed-loop plant stability robustness studies have been carried out assigning a bound on the deviations in LFC system. Numerical results are presented to demonstrate the efficacy of the proposed control design procedure and to evaluate the performance and robustness qualities of the controller.

\section{Plant Model}

Single area power system consists of a governor, a turbine and a generator with feedback of regulation constant. System also includes step load change input to the generator. This work mainly related with the controller unit of a single area power system. Figure 1 shows the block diagram of an uncontrolled isolated power system. The state variable model for the system [1] is

$$
\begin{aligned}
& \dot{x}=A x+B u \\
& y=C x
\end{aligned}
$$

With disturbance w Equation (1) reduces to

$$
\begin{aligned}
& \dot{x}=A x+B u+B_{1} w \\
& y=C x
\end{aligned}
$$

where 


$$
\dot{x}=\left[\begin{array}{c}
\dot{x}_{1} \\
\dot{x}_{2} \\
\dot{x}_{3}
\end{array}\right]=\left[\begin{array}{ccc}
-\frac{1}{T_{H}} & 0 & -\frac{1}{R T_{H}} \\
\frac{1}{T_{T}} & -\frac{1}{T_{T}} & 0 \\
0 & \frac{K_{P}}{T_{P}} & -\frac{1}{T_{P}}
\end{array}\right]\left[\begin{array}{l}
x_{1} \\
x_{2} \\
x_{3}
\end{array}\right]+\left[\begin{array}{c}
\frac{1}{T H} \\
0 \\
0
\end{array}\right] u+\left[\begin{array}{c}
0 \\
0 \\
-\frac{K_{P}}{T_{P}}
\end{array}\right] w, x=\left[\begin{array}{c}
x_{1} \\
x_{2} \\
x_{3}
\end{array}\right]=\left[\begin{array}{c}
\Delta P_{V} \\
\Delta P_{T} \\
\Delta f
\end{array}\right], u=\left[\Delta P_{g}\right], w=\left[\Delta P_{D}\right], y=\left[\begin{array}{lll}
0 & 0 & 1
\end{array}\right] x
$$

Where $\mathrm{A}$ is system matrix, $\mathrm{B}$ is input distribution matrix, $\mathrm{B}_{1}$ is disturbance distribution matrix, $\mathrm{x}$ is state vector, $\mathrm{u}$ is control vector and $\mathrm{w}$ is disturbance vector of load changes.

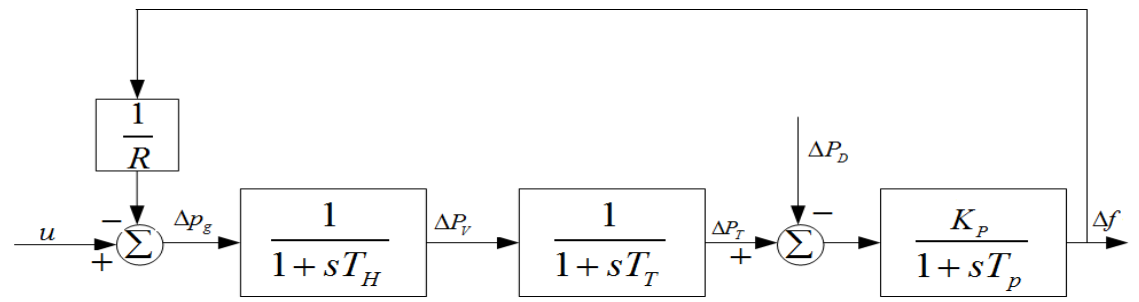

Figure 1: Model of an isolated single area power system.

\section{Proposed Control Scheme}

When the system is subject to uncontrolled disturbances $\mathrm{w}$ due to plant parameter variations (system uncertainties), it is useful to augment the state vector with an extra state variable, the integral of the error signal. The essence of the integral control action is to reduce the frequency deviation to zero.

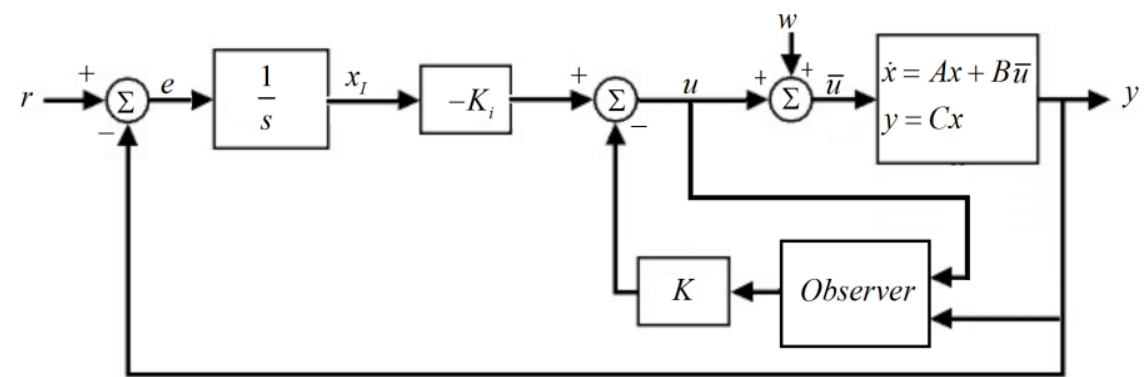

Figure 2: Block diagram for observer with integral control scheme.

For the system described above in Equation (2), the integral action attenuates the steady state error due to the uncontrolled disturbance:

Thus,

$$
\dot{x}_{I}=e=r-y=r-C x
$$

The augmented state equation [3] becomes

$$
x_{I}=\int_{0}^{t} e d t
$$

$$
\left[\begin{array}{l}
\dot{x}_{I} \\
\dot{x}
\end{array}\right]=\left[\begin{array}{rr}
0 & -C \\
0 & A
\end{array}\right]\left[\begin{array}{l}
x_{I} \\
x
\end{array}\right]+\left[\begin{array}{l}
0 \\
B
\end{array}\right] u+\left[\begin{array}{l}
1 \\
0
\end{array}\right] r+\left[\begin{array}{l}
0 \\
B_{1}
\end{array}\right] w
$$

and the feedback law is

$$
u=-\left[\begin{array}{ll}
K_{i} & K
\end{array}\right]\left[\begin{array}{l}
x_{I} \\
x
\end{array}\right]
$$

The choice of $\mathrm{K}_{\mathrm{i}}$ should be such that it should be neither too small nor too large. The integral controller is adjusted for a satisfactory transient response.

\section{Full Order State Observer design}


The design procedure of a linear observer rests on the proper choice of set of matrices with constant elements which determine its performance characteristics [11]. A third-order Luenberger's full state observer [7] is employed to produce the estimates of three state variables $\mathrm{x}_{1}, \mathrm{x}_{2}$ and $\mathrm{x}_{3}$ of the single area power system driven by the available state variable, which is assumed to be available for direct measurement $x_{3}$ and input $u$ having a describing equation of the form

$\dot{z}=D z+C x+G u$

The observer state is $z=\left[\begin{array}{lll}z_{1} & z_{2} & z_{3}\end{array}\right]^{T}$. The observer dynamics is governed by the eigen values of observer system matrix $D=\left[\begin{array}{rrr}0 & 1 & 0 \\ 0 & 0 & 1 \\ -r_{0} & -r_{1} & -r_{2}\end{array}\right]$ which has constant elements and connection matrix $G=\left[\begin{array}{l}g_{1} \\ g_{2} \\ g_{3}\end{array}\right]$. For zero initial conditions, the observer in Equation (3) observes system Equation (1) in a linear manner as per equation $z=T x=\left[\begin{array}{lll}t_{11} & t_{12} & t_{13} \\ t_{21} & t_{22} & t_{23} \\ t_{31} & t_{32} & t_{33}\end{array}\right] x$, where $\mathrm{T}$ is the transformation matrix with constant elements. The Luenberger's compatibility conditions to be satisfied [4] in the design of the observer are

$T A-D T=C$

$G=T B$

The observer poles has to be slightly faster than the controller poles [3] so that the error becomes zero after a short time period. Thus, the eigen values of D-matrix are chosen with sufficiently large negative real parts compared to that of system poles. In our design approach, the eigen value of observer is taken 7 times of eigen values of $(A-B K)$.

Thus for known values of elements of A and B matrices, the elements of T matrices are obtained from Equation (4) using MATLAB program under any operating condition.

Using Equation (5)

$G=T B=\left[\begin{array}{l}g_{1} \\ g_{2} \\ g_{3}\end{array}\right]=\left[\begin{array}{l}b_{1} t_{11} \\ b_{2} t_{21} \\ b_{3} t_{31}\end{array}\right]$

The required estimates may be constructed from Laplace transform of Equation $z(s)=[S I-D]^{-1} C x(s)+[S I-D]^{-1} G u(s)$ and is given by $\hat{x}=T^{-1} z(s)$, which is written as

$\left[\begin{array}{l}\hat{x}_{1} \\ \hat{x}_{2} \\ \hat{x}_{3}\end{array}\right]=\left[\begin{array}{lll}m_{11} & m_{12} & m_{13} \\ m_{21} & m_{22} & m_{23} \\ m_{31} & m_{32} & m_{33}\end{array}\right]\left[\begin{array}{l}z_{1}(s) \\ z_{2}(s) \\ z_{3}(s)\end{array}\right]$

or

$\left[\begin{array}{l}\hat{x}_{1} \\ \hat{x}_{2} \\ \hat{x}_{3}\end{array}\right]=\left[\begin{array}{l}\Delta \hat{P}_{V} \\ \Delta \hat{P}_{T} \\ \Delta \hat{f}\end{array}\right]=\frac{1}{\Delta}\left[\begin{array}{l}\left(a_{o 2} s^{2}+a_{o 1} s+a_{o 0}\right) u(s)+\left(b_{02} s^{2}+b_{o 1} s+b_{o 0}\right) x_{3}(s) \\ \left(c_{o 2} s^{2}+c_{o 1} s+c_{o 0}\right) u(s)+\left(d_{02} s^{2}+d_{o 1} s+d_{o 0}\right) x_{3}(s) \\ \left(e_{o 2} s^{2}+e_{o 1} s+e_{o 0}\right) u(s)+\left(f_{02} s^{2}+f_{o 1} s+f_{o 0}\right) x_{3}(s)\end{array}\right], \Delta=s^{3}+r_{2} s^{2}+r_{1} s+r_{0}$

where

$a_{o 2}, a_{o 1}, a_{o 0}, b_{02}, b_{o 1}, b_{o 0}, c_{o 2}, c_{o 1}, c_{o 0}, d_{02}, d_{o 1}, d_{o 0}, e_{o 2}, e_{o 1}, e_{o 0}, f_{02}, f_{o 1}$ and $f_{o 0}$ are the coefficients of the observer and 
$M=T^{-1}=\left[\begin{array}{lll}m_{11} & m_{12} & m_{13} \\ m_{21} & m_{22} & m_{23} \\ m_{31} & m_{32} & m_{33}\end{array}\right]$

Thus from the light of power system control model shown in Figure (2) and observer design, block diagram of Figure (3) is deduced.

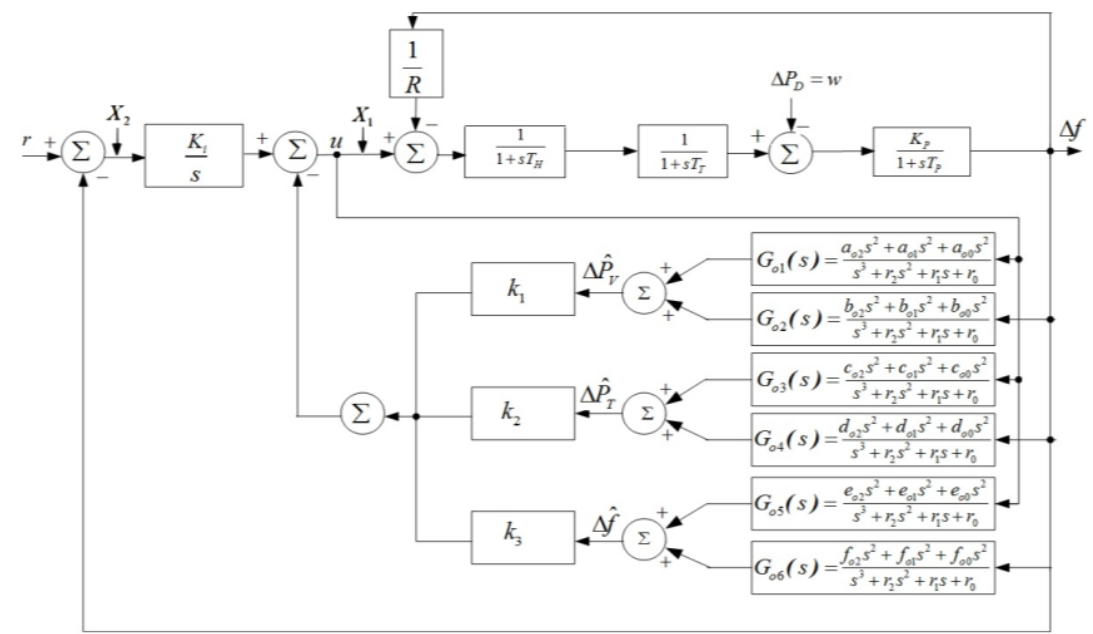

Figure 3: Observer-based full state feedback with integral control.

\section{Closed-loop Pole Locations}

The main objective of optimal regulator or controller design known as linear quadratic regulator (LQR) is to define the performance index (cost function) $\mathrm{J}$ and search for $\mathrm{u}=-\mathrm{Kx}$ that minimizes this index to stabilize the system (i.e. to transfer the system from its initial state to final state such that a given performance index is minimized).

Consider the system $\dot{x}=A x+B u$. The objective is to find the feedback $\mathrm{K}$ of control law such that the performance index $J=\int_{0}^{\infty} \rho y^{2}(t)+u^{2}(t) d t$

is minimized for the system (A, B). Here the optimal value of $\mathrm{K}$ is that which places the closed poles at the stable roots of the symmetric root locus equation [3]

$1+\rho G(-s) G(s)=0$

In standard form

$$
1+\rho \frac{N(-s) N(s)}{D(-s) D(s)}=0
$$

Where $\mathrm{G}(\mathrm{s})$ is the open loop transfer function

$$
G(s)=\frac{y(s)}{u(s)}=\frac{N(s)}{D(s)}=C(S I-A)^{-1} B
$$

and $\rho$ represent weighting penalties on the state variables and control inputs and is chosen by the designer. The controller's performance highly depends on the choice of the weighting factor $\rho$. Wrong choice of these may result to the frequency and power oscillating during disturbances. In reality, choosing different values of $\rho$ can provide us with pole locations that achieve varying balances between a fast response and a low control effort. In practice, usually a value of $\rho$ corresponding to a point close to the knee of the trade-off curve is chosen. This is because it provides a reasonable compromise between the use of control and the speed of response.

\section{Stability Analysis}

The open loop transfer function of the proposed system is obtained by opening its forward path and is solved by Mason's Gain formula for signal flow graph [2]. We consider two loops in our design approach to establish the stability margin in terms of open-loop gain responses. This is in-fact the ability of proposed system 
to deal successfully in-case of model uncertainties. The system is stable when gain values are increased but it may become unstable if the gain increases past a certain critical limit.

Two cases are to be compared in this section, that is by opening the closed loop system of Figure 3 at $\mathrm{X}_{1}$ (inner/internal loop) and at $\mathrm{X}_{2}$ (outer/external loop).

The transfer function of inner loop

$$
G_{X I}(s)=\frac{N_{1} S^{3}+N_{2} S^{2}+N_{3} S+N 4}{D_{1} S^{7}+D_{2} S^{6}+D_{3} S^{5}+D_{4} S^{4}+D_{5} S^{3}+D_{6} S^{2}+D_{7} S+D_{8}}
$$

where,

$$
\begin{aligned}
& \mathrm{N}_{1}=\mathrm{B}_{2} \mathrm{~K}_{\mathrm{p}} \mathrm{R}+\mathrm{K}_{\mathrm{i}} \mathrm{K}_{\mathrm{p}} \mathrm{R}, \mathrm{N}_{2}=\mathrm{B}_{1} \mathrm{~K}_{\mathrm{p}} \mathrm{R}+\mathrm{K}_{\mathrm{i}} \mathrm{r}_{2} \mathrm{~K}_{\mathrm{p}} \mathrm{R}, \mathrm{N}_{3}=\mathrm{B}_{0} \mathrm{~K}_{\mathrm{p}} \mathrm{R}+\mathrm{K}_{\mathrm{i}} \mathrm{r}_{1} \mathrm{~K}_{\mathrm{p}} \mathrm{R}, \mathrm{N}_{4}=\mathrm{K}_{\mathrm{i}} \mathrm{r}_{0} \mathrm{~K}_{\mathrm{p}} \mathrm{R}, \\
& \mathrm{D}_{1}=\mathrm{RH}_{2}, \mathrm{D}_{2}=\mathrm{RH}_{2} \mathrm{r}_{2}+\mathrm{RH}_{1}+\mathrm{RH}_{2} \mathrm{~A}_{2}, \mathrm{D}_{3}=\mathrm{RH}_{2} \mathrm{r}_{1}+\mathrm{RH}_{1} \mathrm{r}_{2}+\mathrm{RH}_{0}+\mathrm{RH}_{2} \mathrm{~A}_{1}+\mathrm{RH}_{1} \mathrm{~A}_{2} \\
& \mathrm{D}_{4}=\mathrm{RH}_{2} \mathrm{r}_{0}+\mathrm{RH}_{1} \mathrm{r}_{1}+\mathrm{RH}_{0} \mathrm{r}_{2}+\mathrm{R}+\mathrm{K}_{\mathrm{p}}+\mathrm{RH}_{2} \mathrm{~A}_{0}+\mathrm{RH}_{1} \mathrm{~A}_{1}+\mathrm{RH}_{0} \mathrm{~A}_{2} \\
& \mathrm{D} 5=\mathrm{RH}_{1} \mathrm{r}_{0}+\mathrm{RH}_{0} \mathrm{r}_{1}+\mathrm{Rr}_{2}+\mathrm{K}_{\mathrm{p}} \mathrm{r}_{2}+\mathrm{RH}_{1} \mathrm{~A}_{0}+\mathrm{RH}_{0} \mathrm{~A}_{1}+\mathrm{RA}_{2}+\mathrm{K}_{\mathrm{p}} \mathrm{A}_{2} \\
& \mathrm{D} 6=\mathrm{RH}_{0} \mathrm{r}_{0}+\mathrm{Rr}_{1}+\mathrm{K}_{\mathrm{p}} \mathrm{r}_{1}+\mathrm{RH}_{0} \mathrm{~A}_{0}+\mathrm{RA}_{1}+\mathrm{K}_{\mathrm{p}} \mathrm{A}_{1}, \mathrm{D}_{7}=\mathrm{Rr}_{0}+\mathrm{K}_{\mathrm{p}} \mathrm{r}_{0}+\mathrm{RA}_{0}+\mathrm{K}_{\mathrm{p}} \mathrm{A}_{0}, \mathrm{D}_{8}=0
\end{aligned}
$$

The transfer function of outer loop

$$
G_{X 2}(s)=\frac{N_{1} S^{3}+N_{2} S^{2}+N_{3} S+N 4}{D_{1} S^{7}+D_{2} S^{6}+D_{3} S^{5}+D_{4} S^{4}+D_{5} S^{3}+D_{6} S^{2}+D_{7} S+D_{8}}
$$

where,

$$
\begin{aligned}
& \mathrm{N}_{1}=\mathrm{K}_{\mathrm{i}} \mathrm{K}_{\mathrm{p}} \mathrm{R}, \mathrm{N}_{2}=\mathrm{K}_{\mathrm{i}} \mathrm{K}_{\mathrm{p}} \mathrm{Rr}_{2}, \mathrm{~N}_{3}=\mathrm{K}_{\mathrm{i}} \mathrm{K}_{\mathrm{p}} \mathrm{Rr}_{1}, \mathrm{~N}_{4}=\mathrm{K}_{\mathrm{i}} \mathrm{K}_{\mathrm{p}} \mathrm{Rr}_{0} \\
& \mathrm{D}_{1}=\mathrm{RH}_{2}, \mathrm{D}_{2}=\mathrm{RH}_{2} \mathrm{r}_{2}+\mathrm{RH}_{1}+\mathrm{RH}_{2} \mathrm{~A}_{2}, \mathrm{D}_{3}=\mathrm{RH}_{2} \mathrm{r}_{1}+\mathrm{RH}_{1} \mathrm{r}_{2}+\mathrm{RH}_{0}+\mathrm{RH}_{2} \mathrm{~A}_{1}+\mathrm{RH}_{1} \mathrm{~A}_{2}, \\
& \mathrm{D}_{4}=\mathrm{RH}_{2} \mathrm{r}_{0}+\mathrm{RH}_{1} \mathrm{r}_{1}+\mathrm{RH}_{0} \mathrm{r}_{2}+\mathrm{R}+\mathrm{K}_{\mathrm{p}}+\mathrm{RH}_{2} \mathrm{~A}_{0}+\mathrm{RH}_{1} \mathrm{~A}_{1}+\mathrm{RH}_{0} \mathrm{~A}_{2} \\
& \mathrm{D}_{5}=\mathrm{RH}_{1} \mathrm{r}_{0}+\mathrm{RH}_{0} \mathrm{r}_{1}+\mathrm{Rr}_{2}+\mathrm{K}_{\mathrm{p}} \mathrm{r}_{2}+\mathrm{RH}_{1} \mathrm{~A}_{0}+\mathrm{RH}_{0} \mathrm{~A}_{1}+\mathrm{RA}_{2}+\mathrm{K}_{\mathrm{p}} \mathrm{A}_{2}+\mathrm{K}_{\mathrm{p}} \mathrm{RB}_{2} \\
& \mathrm{D}_{6}=\mathrm{RH}_{0} \mathrm{r}_{0}+\mathrm{Rr}_{1}+\mathrm{K}_{\mathrm{p}} \mathrm{r}_{1}+\mathrm{RH}_{0} \mathrm{~A}_{0}+\mathrm{RA}_{1}+\mathrm{K}_{\mathrm{p}} \mathrm{A}_{1}+\mathrm{K}_{\mathrm{p}} \mathrm{RB}_{1}, \\
& \mathrm{D}_{7}=\mathrm{Rr}_{0}+\mathrm{K}_{\mathrm{p}} \mathrm{r}_{0}+\mathrm{RA}_{0}+\mathrm{K}_{\mathrm{p}} \mathrm{A}_{0}+\mathrm{K}_{\mathrm{p}} \mathrm{RB}_{0}, \mathrm{D}_{8}=0 \\
& \text { and } \\
& \mathrm{A}_{2}=\mathrm{a}_{02} \mathrm{k}_{1}+\mathrm{c}_{\mathrm{o} 2} \mathrm{k}_{2}+\mathrm{e}_{\mathrm{o} 2} \mathrm{k}_{3}, \mathrm{~A}_{1}=\mathrm{a}_{\mathrm{o}} \mathrm{k}_{1}+\mathrm{c}_{\mathrm{o} 1} \mathrm{k}_{2}+\mathrm{e}_{\mathrm{o}} \mathrm{k}_{3}, \mathrm{~A}_{0}=\mathrm{a}_{\mathrm{o}} \mathrm{k}_{1}+\mathrm{c}_{\mathrm{o} 0} \mathrm{k}_{2}+\mathrm{e}_{\mathrm{o}} \mathrm{k}_{3}, \\
& \mathrm{~B}_{2}=\mathrm{b}_{\mathrm{o} 2} \mathrm{k}_{1}+\mathrm{d}_{\mathrm{o} 2} \mathrm{k}_{2}+\mathrm{f}_{\mathrm{o} 2} \mathrm{k}_{3}, \mathrm{~B}_{1}=\mathrm{b}_{\mathrm{o} 1} \mathrm{k}_{1}+\mathrm{d}_{\mathrm{o} 1} \mathrm{k}_{2}+\mathrm{f}_{\mathrm{ol}} \mathrm{k}_{3}, \mathrm{~B}_{0}=\mathrm{b}_{\mathrm{o} 0} \mathrm{k}_{1}+\mathrm{d}_{\mathrm{o} 0} \mathrm{k}_{2}+\mathrm{f}_{\mathrm{o} 0} \mathrm{k}_{3}, \\
& \mathrm{H}_{2}=\mathrm{T}_{\mathrm{H}} \mathrm{T}_{\mathrm{T}} \mathrm{T}_{\mathrm{p}}, \mathrm{H}_{1}=\mathrm{T}_{\mathrm{H}} \mathrm{T}_{\mathrm{T}}+\mathrm{T}_{\mathrm{H}} \mathrm{T}_{\mathrm{p}}+\mathrm{T}_{\mathrm{T}} \mathrm{T}_{\mathrm{p}}, \mathrm{H}_{0}=\mathrm{T}_{\mathrm{H}}+\mathrm{T}_{\mathrm{T}}+\mathrm{T}_{\mathrm{p}}
\end{aligned}
$$

Two commonly used quantities that measure the stability margin for such system are the gain margin (GM) and phase margin (PM). This is discussed in next section with respect to Bode plots of GM and PM.

\section{Simulation and Results}

With an objective to meet the specifications $\mathrm{GM} \geq 6 \mathrm{~dB}, \mathrm{PM} \geq 40$ degree and no frequency deviations in the steady-state, a full state observer with integral control has been designed for the LFC model. A typical operating condition has been chosen as the nominal values of the parameters of the LFC model are shown in Table 1. A deviation of $\pm 10 \%$ on the nominal values of the parameters of LFC model has been considered for investigation of stability issues of the designed control scheme in Figure 3 for LFC model.

The closed-loop pole (CLP) locations have been chosen from the SRL plot for the equation (9) as shown in Figure 4. The closed-loop integrator pole location is given by $s=-\rho_{\mathrm{i}}$. With the help of three closedloop poles from SRL plot and one properly selected closed-loop integrator pole, feedback gain constants $\mathrm{K}_{\mathrm{i}}, \mathrm{k}_{1}$, $\mathrm{k}_{2}$ and $\mathrm{k}_{3}$ are obtained using augmented state model.

The third-order observer has been designed with its pole locations are at seven times the controller pole locations (obtained from SRL plot) to determine D-matrix. The matrices T, G and M have been determined using Equations (4), ( 6) and ( 8) respectively.

The open-loop transfer functions $\mathrm{G}_{\mathrm{X} 1}(\mathrm{~s})$ and $\mathrm{G}_{\mathrm{X} 2}(\mathrm{~s})$ have been determined using equations (10) and (11) respectively for stability margins analysis. Figure 5 indicates the variations in GM and PM at $\mathrm{X}_{1}$ with $\rho$ for various values of $\rho_{\mathrm{i}}$. It is observed that the GM and the PM remain almost constant with $\rho$ in the higher range, but they vary appreciably with $\rho_{\mathrm{i}}$. The critical PM occurs corresponds to loop opening at $X_{1}$. In this paper, $\rho=600$ and $\rho_{\mathrm{i}}=7$ have been selected to satisfy $\mathrm{GM} \geq 6 \mathrm{~dB}$ and $\mathrm{PM} \geq 40$ degree. Table 2 shows the closed-loop pole locations and controller gains.

The results of performance studies obtained by MATLAB simulations for the selected operating points are provided in Table 3 and 4 . The results describing the disturbance rejection property for various load demand changes have been shown in Figure 6.

Table 1: Area parameter values 


\begin{tabular}{|c|c|c|c|c|c|}
\hline Area Parameter & $\mathrm{R}(\mathrm{puHz} / \mathrm{Mw})$ & $\mathrm{T}_{\mathrm{H}}(\mathrm{sec})$. & $\mathrm{T}_{\mathrm{T}}(\mathrm{sec})$. & $\mathrm{T}_{\mathrm{p}}$ (sec.) & $\mathrm{K}_{\mathrm{p}}(\mathrm{puHz} / \mathrm{Mw})$ \\
\hline Nominal value & 2.4 & 0.08 & 0.3 & 20 & 120 \\
\hline $\begin{array}{l}\text { Nominal value } \\
\quad+10 \%\end{array}$ & 2.64 & 0.088 & 0.33 & 20 & 109 \\
\hline Nominal value $-10 \%$ & 2.16 & 0.072 & 0.27 & 20 & 133 \\
\hline
\end{tabular}

Table 2: Closed-loop pole locations and associated gains.

\begin{tabular}{|cccc|}
\hline CLP for & CLP locations & Observer poles & Controller gains \\
& & & \\
& $\lambda_{2=}=600$ & $\mathrm{r}_{2}=-276.06$ & $\mathrm{~K}_{\mathrm{i}}=171.49$ \\
$\rho_{\mathrm{i}}=7$ & $\lambda_{1=-9.68+14.54 i}$ & $\mathrm{r}_{1}=-34000.55$ & $\mathrm{k}_{1}=2.44$ \\
& $\lambda_{0=-9.68-14.54 \mathrm{i}}$ & $\mathrm{r}_{0}=-2100753.59$. & $\mathrm{k}_{2}=19.78$ \\
& & $\mathrm{k}_{3}=43.32$ \\
& & & \\
& & & \\
\end{tabular}

Table 3: Result of frequency response studies on proposed system.

\begin{tabular}{|c|c|c|c|c|c|}
\hline Loop break at & Perturbation & PCF (rad/sec) & GM (dB) & GCF (rad/sec) & PM (deg) \\
\hline $\mathrm{X}_{1}$ & Nominal & 96.12 & 11.85 & 25.86 & 41.16 \\
& $+10 \%$ & 87.56 & 11.72 & 23.81 & 40.91 \\
& $-10 \%$ & 106.46 & 11.99 & 28.32 & 41.45 \\
\hline $\mathrm{X}_{2}$ & Nominal & 15.38 & 12.14 & 3.92 & 69.96 \\
& $+10 \%$ & 14.18 & 11.80 & 3.76 & 69.18 \\
& $-10 \%$ & 16.82 & 12.54 & 4.10 & 70.84 \\
\hline
\end{tabular}

Table 4: Settling time at varying load demands.

\begin{tabular}{|c|c|c|c|}
\hline Load demand & Perturbation & Settling time $(\mathrm{sec})$ & $\begin{array}{c}\text { Maximum variation in } \\
\text { frequency }(\mathrm{Hz})\end{array}$ \\
\hline $10 \%$ & Nominal & 0.392 & $4.02 \mathrm{e}-004$ \\
& $+10 \%$ & 0.426 & $5.3 \mathrm{e}-004$ \\
& $-10 \%$ & 0.358 & $2.49 \mathrm{e}-004$ \\
\hline $20 \%$ & Nominal & 0.393 & $8.02 \mathrm{e}-004$ \\
& $+10 \%$ & 0.427 & $10.6 \mathrm{e}-004$ \\
& $-10 \%$ & 0.358 & $4.99 \mathrm{e}-004$ \\
\hline
\end{tabular}

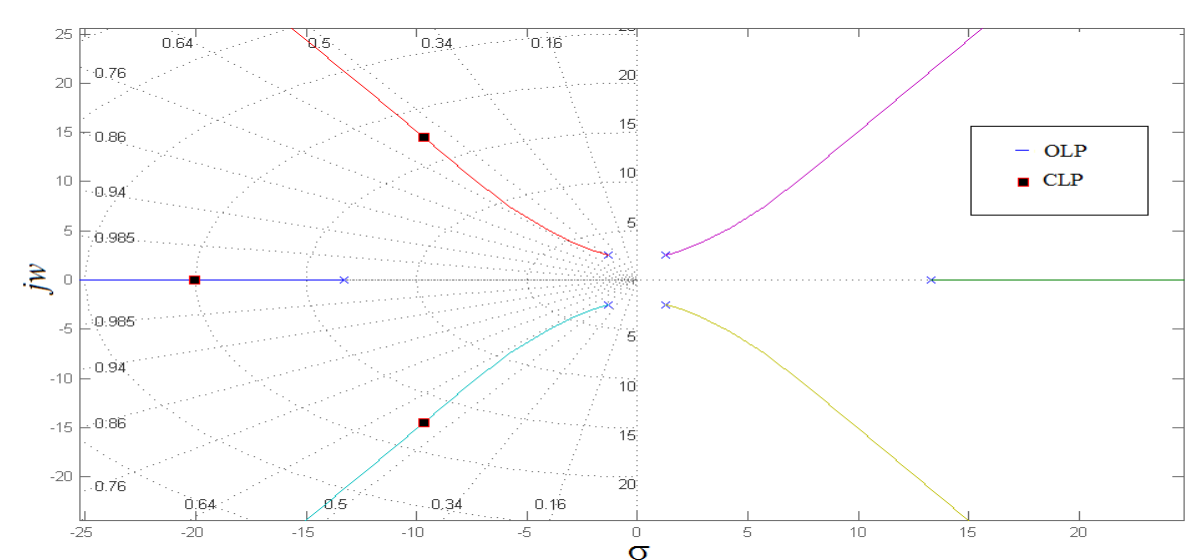

Figure 4: Symmetrical root locus diagram with selected closed-loop poles. 

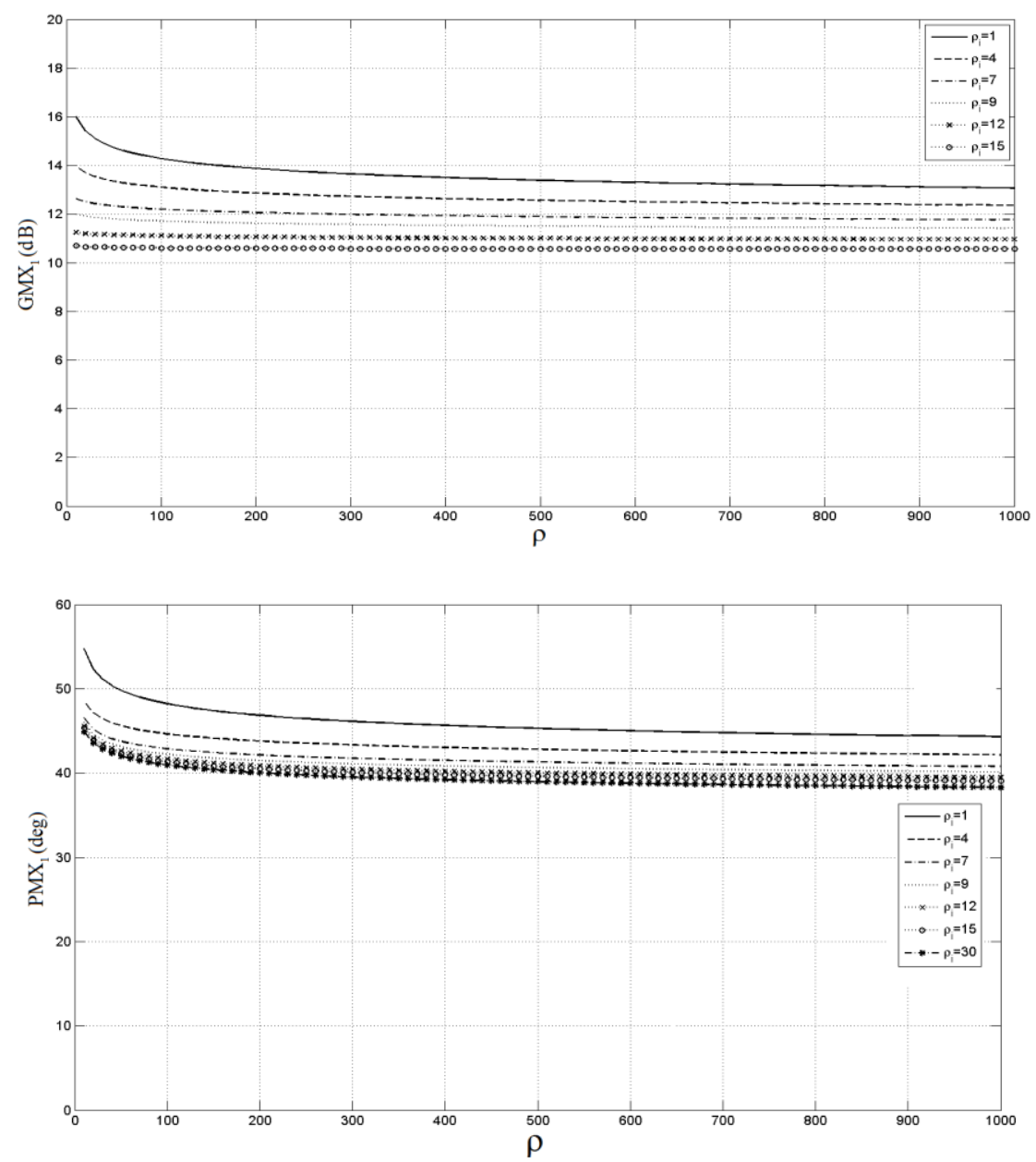

Figure 5: GM and PM of the open-loop system at $X_{1}$ under varying values of $\rho$ and $\rho_{\mathrm{i}}$.

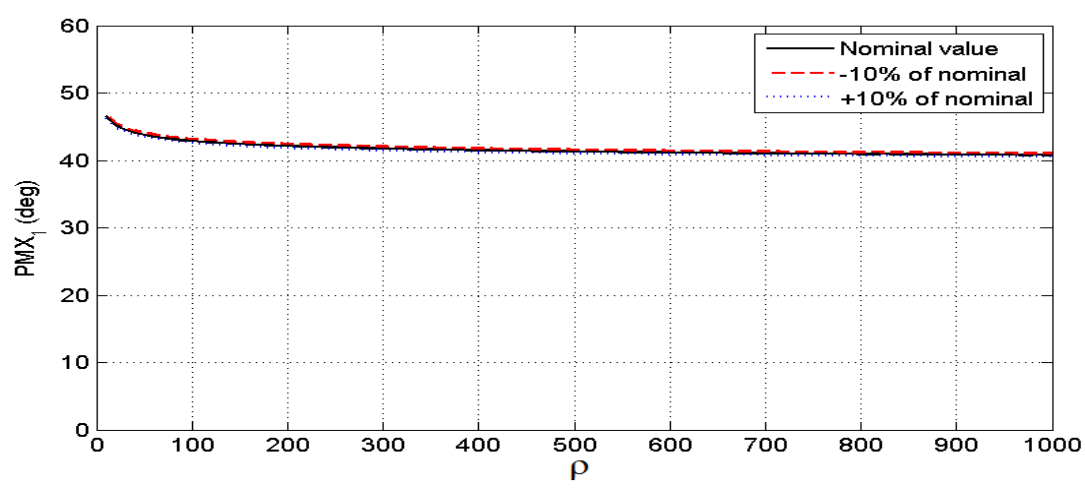

Figure 6: Frequency responses under parameter variations.

Figure 7 shows the frequency deviations for the various load demands. That is, the control effort increases with increase in $\Delta \mathrm{P}_{\mathrm{D}}$, thus for a certain higher value of $\Delta \mathrm{P}_{\mathrm{D}}$, actuator can saturate [9].

Figures 8 denotes the dynamic response of the observer estimates. This in-fact shows the ability of the proposed strategy, that it is capable of measuring all the states (unknown and known). Thus, the need for sensors are eliminated, which are otherwise costly or may be noisy. The deviation in $\Delta \hat{P}_{V}$ and $\Delta \hat{P}_{T}$ are observed between the observed and the actual values. 


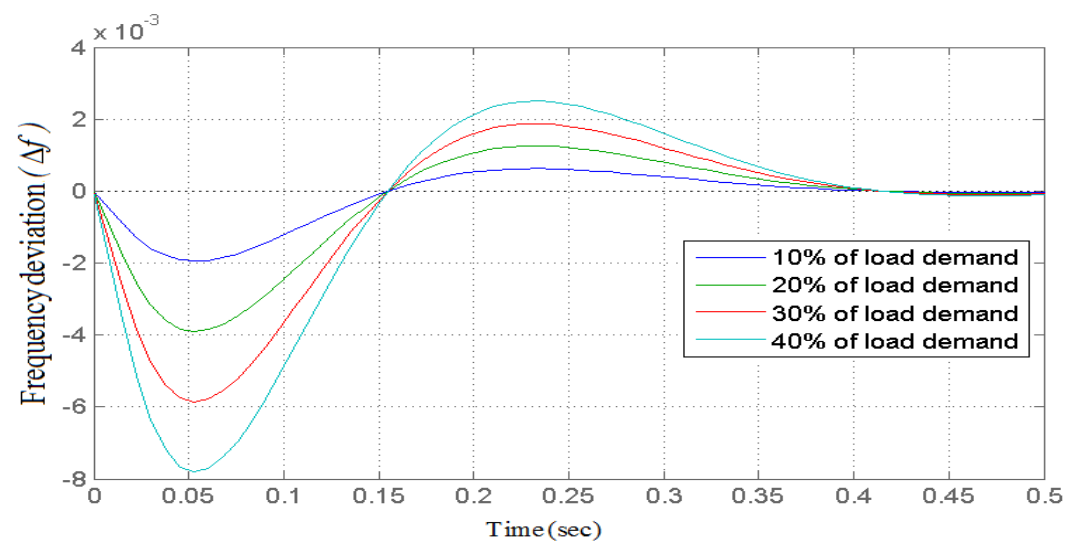

Figure 7: Dynamic response of system under varying values of load demands.

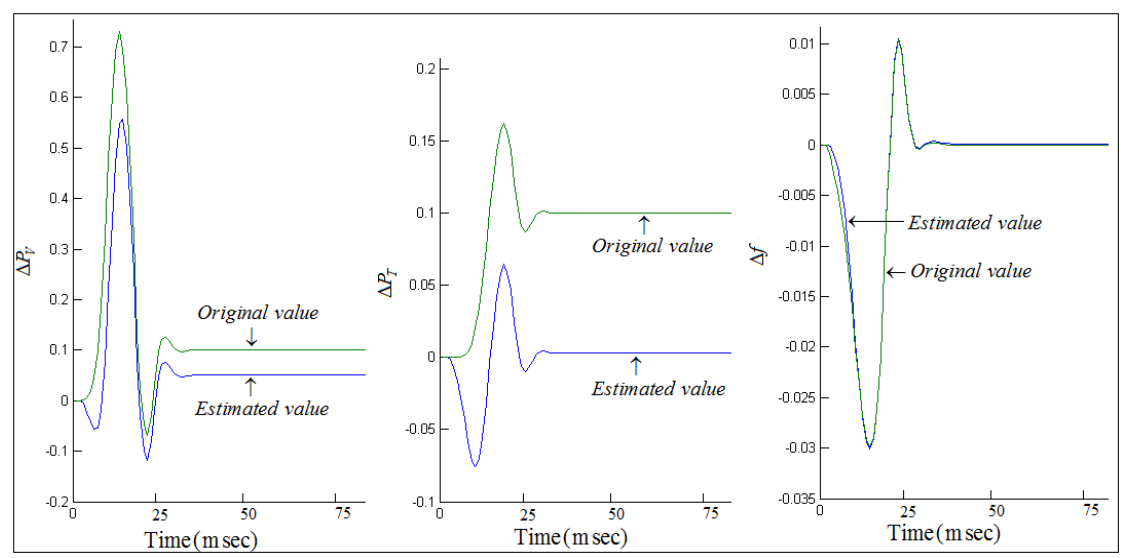

Figure 8: Dynamic responses of observer estimates.

\section{Conclusion}

Implementation of full state feedback offers a scope for design trade-off between speed of response and the capabilities of hardware resources, assuring desired stability performance quality. It may be possible to fully utilize the capability of actuator, as the proposed method provides some control over peak values of $\Delta \mathrm{f}, \Delta \mathrm{P}_{\mathrm{V}}$ and $\Delta \mathrm{P}_{\mathrm{T}}$. The proposed design methodology provides a systematic analysis and design steps in order to achieve desired performance for the observer-based LFC. At the expense of some additional computational burden for the observer system, the proposed method is inexpensive to implement requiring no additional sensors. The observer has been incorporated in terms of transfer functions in order to carry out stability analysis easily. The robust disturbance rejection capability and maintaining stability in the face of model parametric uncertainties have been demonstrated by the numerical examples.

The present linear analysis does not take into account the effects of various non-linearities and delays introduced by sampling and computation. However, control gains obtained by the proposed design may be used as initial guess values in presence of non-linearities.

\section{References}

[1] Olle 1. Elgerd, Electric Energy Systems Theory; An Introduction (2nd Edition, McGraw-Hill Inc. 1982).

[2] K. Ogata, Modern Control Engineering (4th edition, Prentice Hall Inc. 2002).

[3] Gene F. Franklin, David Powell and Abbas Emami-Naeini, Feedback Control of Dynamic Systems (4th Edition, Pearsons Education Inc. 2002).

[4] S.K. Goswami and K. Datta, On estimation errors in linear systems due to parametric variations, Journal of the institute of engineers (India), vol. 86, Dec. 2005, p(s) 192.

[5] D.P. Kothari and I.J. Nagrath, Modern Power system Analysis (3rd Edition, Tata McGraw-Hill Inc. 2003).

[6] S.K. Goswami, On a Certain Structural Property of a Linear Observer, M.E.E. Thesis, Jadavpur University, 1968.

[7] D.G. Luenberger, An Introduction to Observers: I.E.E.E. Transactions, Vol. AC-16, 1971, p(s): 596-602.

[8] P. Kundur, Power System Stability and Control (McGraw-Hill Inc. 1994).

[9] Robert L. Williams II and Douglas A. Lawrence, Linear State-Space Control Systems (John Wiley \& Sons, Inc. 2007).

[10] Prof. D.P. Kothari, Centre for Energy Studies on Automatic Generation Control, IIT Delhi, Lecture 24.

[11] R.K. Mehta, S.K. Goswami and K. Datta, An observer-based lateral autopilot for tail-controlled missiles, IE(I) Journal-EL, Vol 88, sept. 2007, p(s): 17-22. 